\title{
The long-term effectiveness of generic adult fixed-dose combination antiretroviral therapy for $\mathrm{HIV}$-infected Ugandan children
}

*Barlow-Mosha LN ${ }^{1}$, Bagenda DS ${ }^{1,4}$, Mudiope $\mathrm{PK}^{1}$, Mubiru MC ${ }^{1}$, Butler $\mathrm{LM}^{5}$, Fowler $\mathrm{MG}^{3}$, Musoke $\mathrm{PM}^{1,2}$

1. Makerere University- Johns Hopkins University Research Collaboration (MU-JHU)

2. Department of Paediatrics, Makerere University Mulago, Kampala, Uganda

3. Johns Hopkins University

4. Department of Epidemiology and Biostatistics, Makerere University School of Public Health

5. University of California San Francisco, Department of Epidemiology and Biostatistics; Institute for Global Health.

\begin{abstract}
Background: Access to pediatric antiretroviral formulations is increasing in resource-limited countries, however adult FDCs are still commonly used by antiretroviral therapy (ART) programs.

Objective: To describe long-term effectiveness of using adult FDC of d4T+3TC+NVP (Triomune) in children for HIV treatment.

Methods: Clinical, immunologic, and virologic outcomes of HIV-infected ART-naïve children aged six months to 12 years, were evaluated up to 96 weeks post-ART initiation.

Results: From March 2004 to June 2006, 104 children were followed with a median age of 5.4 years, median CD4 cell percent and HIV-1 RNA were 11.0\% (IQR 6.7-13.9) and 348,846copies/mL (IQR 160,941-681,313) respectively at baseline. Using Kaplan-Meir estimates, $75 \%$ of children had undetectable viral loads ( $<400$ copies $/ \mathrm{mL})$ at 96 weeks of ART. Children with a baseline CD 4 cell percent $>15 \%$ were 3 times more likely to achieve viral load $<400$ copies $/ \mathrm{mL}$ than those with baseline CD4 cell percent $<5 \%$ after adjusting for baseline age $\{\mathrm{aHR}=3.03(1.10-8.32), \mathrm{p}=0.03\}$; no difference was found among those with CD4 cell percent $>5-14.9 \%$ and $<5 \%$.

Conclusion: Treatment with generic adult FDC for HIV-infected Ugandan children led to sustained clinical, immunologic and virologic response during 96 weeks of ART. Early initiation of ART is key to achieving virological success.
\end{abstract}

Key words: Children, HIV, antiretroviral treatment, Sub-Saharan Africa, fixed dose combination African Health Sciences 2012; 11(3): 249 - 258 http://dx.doi.org/10.4314/ahs.v12i3.2

\section{Introduction}

Ninety percent of the estimated two million HIVinfected children worldwide in 2009 lived in subSaharan Africa and an estimated 370,000 are infected annually ${ }^{1}$. Where available, access to HIV care and treatment has improved the survival and the overall quality of life of HIV-infected children ${ }^{2,3}$. In addition, the limited infrastructure for treatment of HIVinfected children, including access to early infant HIV diagnosis, availability of trained health staff to deliver paediatric services, and inadequate tools for monitoring ART have made scale up of paediatric ART lag behind the expansion of adult programs ${ }^{4}$.

\begin{tabular}{l} 
*Correspondence author: \\
Dr. Linda N. Barlow-Mosha \\
MUJHU Care Ltd/MUJHU Research \\
Collaboration \\
P. O. Box 23491 \\
Kampala, Uganda \\
Telephone No: 256-414-541044 \\
Email: lbarlow@mujhu.org \\
\hline
\end{tabular}

African Health Sciences Vol 12 No 3 September 2012
In 2010, approximately 120,000 children were living with HIV/AIDS in Uganda ${ }^{5}$. Although over 260,000 HIV-infected individuals are on HAART in Uganda, fewer than 22,000 (8\%) are children $<15$ years of age $^{5}$. While the price of antiretroviral drugs has significantly decreased due to competition from generic drug manufacturers, pediatric drug formulations still cost up to ten times more than adult formulations for the same drug regimens ${ }^{6}$. While pediatric fixed dose combination are now steadily becoming available in resource-limited settings, adult FDCs are still being used to treat children especially in rural areas. Triomune, an adult generic fixed dose combination (FDC) tablet manufactured by CIPLA, India is widely available and used in many ART programs. Studies in subSaharan Africa have found good clinical and immunologic outcomes among children who received adult FDCs followed for 6 to 12 months ${ }^{7-}$ 10. However, few studies have reported virologic outcomes in resource-limited settings, beyond 6-12 
months of treatment ${ }^{8,9,11,12}$. Concerns have been raised about the effectiveness of these adult formulations for the treatment of HIV-infected children and long-term virologic data is limited. The objective of our study was to assess the long-term effectiveness of using Triomune, an adult FDC tablet, in the treatment of HIV-infected children by monitoring their clinical, immunologic and virologic treatment outcomes over a 96-week period.

\section{Methods}

\section{Participant selection}

Participants were HIV-infected children who were enrolled between March 2004 and May 2006 in a pediatric ART program, which was funded by the Elizabeth Glaser Pediatric AIDS Foundation International Leadership Award, at Makerere University-Johns Hopkins University Research Collaboration (MU-JHU) Kampala, Uganda. Children between 6 months and 12 years of age were screened for HAART eligibility at the MUJHU clinic as described in detail elsewhere ${ }^{13}$. Prior to HAART initiation, all children and their caregivers were assessed for psychosocial and behavioral readiness, and education on adherence to care and treatment was provided over the course of three sessions. Those children who did not meet the ART eligibility criteria were referred back to Mulago Hospital for follow-up and care.

Upon determination of HAART eligibility and completion of the 3 pre-enrollment visits (described above), children received either a FDC (Triomune 30 [30mg d4T, $150 \mathrm{mg}$ 3TC, $200 \mathrm{mg}$ NVP] or Triomune 40 [40mg d4T, $150 \mathrm{mg}$ 3TC, $200 \mathrm{mg} \mathrm{NVP]}$ ), or syrup formulation of $\mathrm{d} 4 \mathrm{~T}$ or zidovudine $(\mathrm{AZT})+3 \mathrm{TC}+\mathrm{NVP} / \mathrm{EFV}$. Some of the children enrolled in the program were co-enrolled in a study that has been previously reported that was assessing the effectiveness of NVP based regimens in children who have and have not been exposed to single dose NVP at birth ${ }^{13}$. The study was reviewed and approved by the Makerere University Faculty of Medicine institutional review board ${ }^{13}$. For those co-enrolled in the study, informed consent was obtained from parent/caretaker before any study procedures were conducted, however written assent was not obtained from the children since it was not a requirement by the IRB at that time. For the present analysis, only the children initiated on the FDCs were included. Children who were initiated on syrup formulations or a zidovudine-containing regimen were excluded from this analysis.
Table 1: Weight band dosing used for the study children

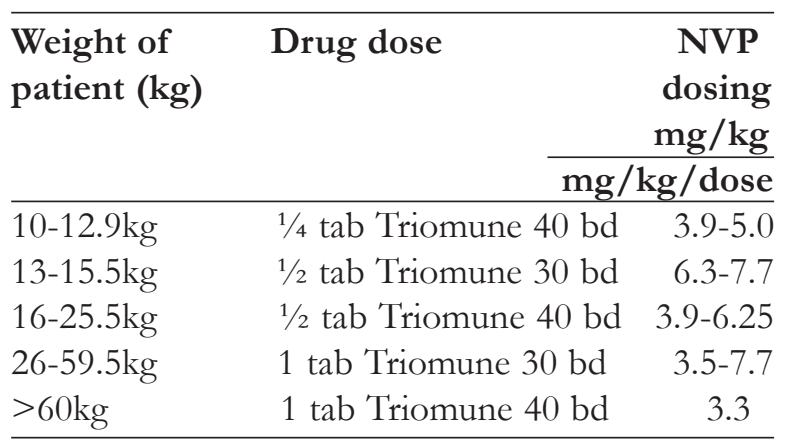

The Triomune tablet was dosed based on the child's weight (table1) ${ }^{13}$. These weight bands were developed prior to the 2006 WHO dosing guidelines for children in resource-constrained settings $\mathrm{s}^{13,14}$. The tablets were either halved or quartered and were precut by the staff pharmacist with a pill cutter. In January 2007, the children on a quarter tablet were switched to half a tablet due to results from a pharmacokinetic study ${ }^{15}$. Children who developed a rash due to NVP hypersensitivity stopped Triomune and were switched to an alternative regimen that included efavirenz (EFV). A child was considered to have failed therapy if there was inadequate weight gain and or increasing WHO clinical staging and or a greater than $30 \%$ decline in CD4 cell count/percent $\geq 12$ weeks after start of Triomune therapy ${ }^{16}$. The presence of detectable viral load did not lead to change of therapy if the child was clinically stable and the CD4 cell count was not declining. However, all these decisions were made in consultation with the study team and the consultants. For this analysis, virologic failure was defined as two viral loads $>400$ copies $/ \mathrm{ml}$ after 24 weeks of ART. Only those who failed first-line regimen of Triomune (with both clinical and virologic failure) were changed to a second line regimen [abacavir $(\mathrm{ABC})+$ didanosine $(\mathrm{DDI})+$ lopinavir/ritonavir $(\mathrm{LPV} / \mathrm{r})]$. None of the children were switched to second line therapy during the 96week period due recommended guidelines at the time, where a child could remain on a failing regimen as long as $\mathrm{s} / \mathrm{he}$ was clinically stable and immunologically responding to therapy due to limited second line treatment options.

Following HAART initiation, children were followed at clinic visits scheduled every week for the first month, every two weeks for the second month, and then every four weeks until 48 weeks, and thereafter every 12 weeks until 96 weeks. At each follow-up 
visit, anthropometric measurements were recorded and a physical exam was performed, as was clinical staging based on the 2003 WHO staging for infants and children ${ }^{14}$. Children also received multivitamins, cotrimoxazole prophylaxis, and free medication for all acute illnesses. Caregivers and children with partial or full disclosure, received adherence counseling at each scheduled follow-up visit. Patients and caregivers were reminded about adherence to treatment and occasionally home visits were made if a problem with adherence was identified. Caregivers were provided with a 30-day supply of medication for their child each month.

\section{Measurements}

Drug Adberence: Adherence monitoring was conducted at each follow-up visit and was based on pill counts (dividing the actual number of pills taken by the number of pills prescribed) as presented elsewhere ${ }^{17}$. Additional adherence information was collected from children, depending on their developmental age and disclosure status. An adherence rate $\geq 95 \%$ was defined as acceptable ${ }^{18-20}$. Anthropometric measurements. Height-for-age z score (HAZ) and weight-for-age $z$ score (WAZ) were calculated using WHO growth standard reference ranges. Clinical response was analyzed only using HAZ and WAZ.

Laboratory measurements. Participants had blood drawn at baseline for measurement of complete blood cell count (CBC), CD4 cell count/percent, liver transaminases (AST and ALT) and renal function (creatinine) tests, and plasma HIV-1 RNA. Blood was collected at follow-up visits for repeat CBCs, CD4 cell counts/percents, and plasma HIV-1 RNA levels at 12, 24, 36, 48, 72 and 96 weeks after HAART initiation. Toxicities were graded using the DAIDS Toxicity tables 2004. All laboratory tests were performed at the MU-JHU Core Lab, Kampala Uganda, which is certified by the College of American Pathologists. CD4 cell counts/percents were assessed by BD FACSCalibur instrument (Becton, Dickinson \& Company). Plasma HIV RNA levels were measured using the Amplicor HIV-1 Monitor test, version 1.5 Standard assay (Roche Company, Branchburg, New Jersey/USA). Plasma HIV-1 RNA levels $>750,000$ copies/mL were diluted and further assessed by dilution. HIV-1 RNA levels that were $<400$ copies $/ \mathrm{mL}$ were considered undetectable for the purpose of this analysis.

\section{Statistical analysis}

All data used for analysis were checked for accuracy and entered into a Microsoft Access database. Descriptive statistics were calculated including means, standard deviations, medians and inter-quartile ranges. Proportions and 95\% confidence intervals (CI) of participant characteristics were calculated. HAZ and WAZ of participants were calculated, with respect to the WHO-based reference population of children of similar age and gender. For the present analysis, the primary endpoint was achievement of sustained viral load $<400$ copies/mL Estimates of conditional probabilities of achieving this endpoint through 96 weeks following initiation of antiretroviral treatment were calculated using Kaplan-Meier (K-M) statistics. Differences between $\mathrm{K}-\mathrm{M}$ curves were assessed for statistical significance using the log-rank test. Cox regression analyses were used to indicate the hazard ratios (HR) associated with baseline characteristics. All statistical analyses were assessed for statistical significance at $?=0.05$. All statistical analyses were performed using STATA Version 10 (StataCorp. 2007. Stata Statistical Software: Release 10. College Station, TX: StataCorp LP).

\section{Results \\ Participant characteristics}

Between March 2004 and May 2006, 130 of 230 $(55.2 \%)$ children screened were eligible for HAART initiation and enrolled to the parent ART program. (figure 1) One hundred were not eligible to start HAART mostly due to high CD4 cell count count/ percent. Other reasons for ineligibility in descending order were active tuberculosis infection, nondisclosure, HIV negative, weight below $10 \mathrm{~kg}$, death, psychosocial issue thought to potentially affect adherence, and failure to return to clinic. Of the 130 children who were enrolled into the parent ART program, 26 were initiated on a syrup formulation of $\mathrm{d} 4 \mathrm{~T} / \mathrm{AZT}+3 \mathrm{TC}+\mathrm{NVP}$ due to a baseline weight $<10 \mathrm{~kg}$ and were thus excluded from the present analysis. 
Figure 1: Program profile

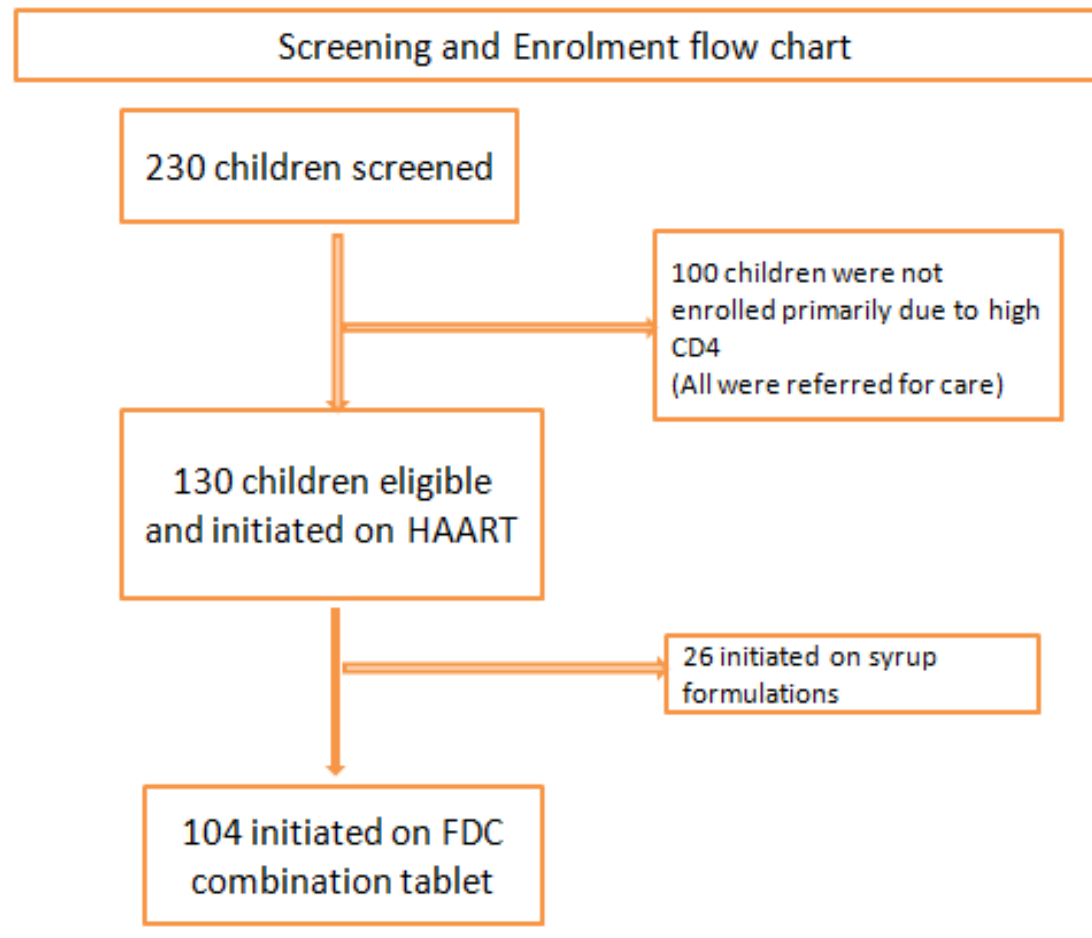

Baseline characteristics of 104 children included in this analysis are described in Table 2. The median age of the children who initiated Triomune was 5.4 years (IQR 2.7-7.9), 50\% were female, and 79\% presented with WHO stage II or III disease at baseline. The overall baseline median CD4 cell percent was $11 \%$ (IQR 6.7-13.9) and the median viral load was 348,846 copies/mL (IQR 169,941-
681,313). Proportionately more children $\geq 6$ years [13/45 (29\%)] were initiated on HAART with a baseline CD 4 cell percent $<5 \%$ compared to children $3-5.9$ years $[4 / 31(13 \%)]$ and children $<3$ years of age $[2 / 28(7 \%)]$. The median follow-up time was 96 weeks (IQR 72-97). There were no children lost to follow-up.

Table 2: Baseline characteristics of HIV-infected Ugandan children before initiation of generic adult FDC ART (Triomune)

\begin{tabular}{ll}
\hline Characteristic & All patients(n= 104) \\
\hline Median Age years (IQR) & $5.4(2.7-7.9)$ \\
Number of children $<3$ years & 28 \\
Number of children 3- 5.9 years & 31 \\
Number of children $\geq$ 6 years & 45 \\
WHO Clinical Stage Classification 2003 & \\
Stage I & $22(21 \%)$ \\
Stage II & $55(54 \%)$ \\
Stage III & $27(25 \%)$ \\
Sex & \\
Female & $52(50 \%)$ \\
Mean weight-for-age z-score (SD) & $-1.34(1.19)$ \\
Mean height-for-age z-score (SD) & $-2.27(1.20)$ \\
Overall Median CD4 cell percent (IQR) & $11.0(6.7-13.9)$ \\
Overall Median HIV Viral Load copies/mL (IQR) & $348,846(160,941-681,313)$ \\
Overall Mean Viral Log I $_{10}$ copies & $5.5(5.2-5.8)$ \\
\hline
\end{tabular}




\begin{tabular}{lc}
\hline Characteristic & All patients(n= 104) \\
\hline Median CD4 cell percent (IQR) stratified by age & \\
$<3$ years & $11.9(10.0-15.0)$ \\
3- 5.9 years & $10.0(6.7-14.7)$ \\
$\geq 6$ years & $8.9(3.8-13.1)$ \\
Number of children stratified by baseline CD4 cell percent \\
$<5 \%$ & $19(18 \%)$ \\
$5-15 \%$ & $70(68 \%)$ \\
$>15 \%$ & $14(14 \%)$ \\
Mean viral $\log _{10}$ copies stratified by age (SD) & \\
$<3$ years & $5.8(0.35) *$ \\
$3-5$ years & $5.1(0.89)$ \\
$\geq 6$ years & $5.2(0.65)$ \\
\hline Note: SD- standard deviation, IQR - Interquartile Range, $*$ Kruskal-Wallis rank test, $\mathrm{p}<0.001$
\end{tabular}

\section{Virologic response to treatment}

Using K-M estimations $44 \%$ of children achieved sustained undetectable HIV RNA levels $(<400$ copies per $\mathrm{mL}$ ) by 12 weeks following HAART initiation and by 96 weeks approximately threequarters $(75 \%)$ of children had undetectable HIV RNA levels (figure 2a). Overall, the median time to initial sustained viral suppression ( $<400$ copies $/ \mathrm{mL}$ ) was 24 weeks (95\% CI 12-24). The median time to

Figure 2a: Proportion of children on generic adult FDC HAART (Triomune) achieveing viral load $<400$ copies/ML

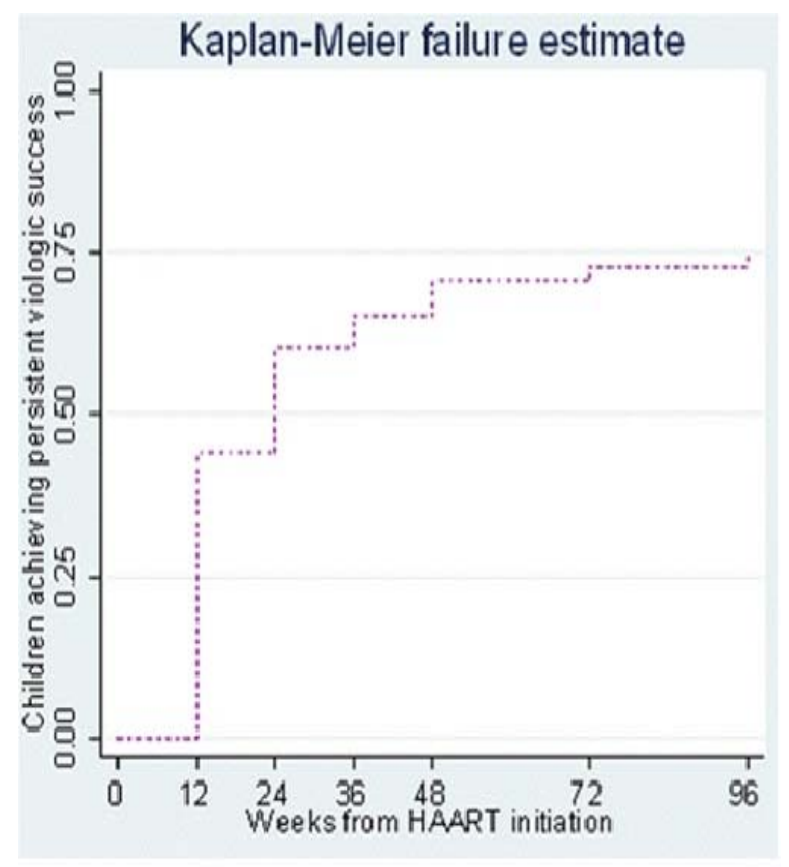

achieve viral suppression was similar regardless of age. Children with baseline CD4 cell $>15 \%$ had a median survival time to undetectable VL that was significantly lower than that of children with baseline CD 4 cell $<5 \%$ or $5-14.9 \%$ ( $\mathrm{p}$ value for log rank test for trend $=0.02$ ) (figure $2 \mathrm{~b}$ ).

Figure 2b: Proportion of children on generic adult FDC HAART (Triomune) achieveing viral load $<400$ copies/ML stratified by baseline CD4 cell percent

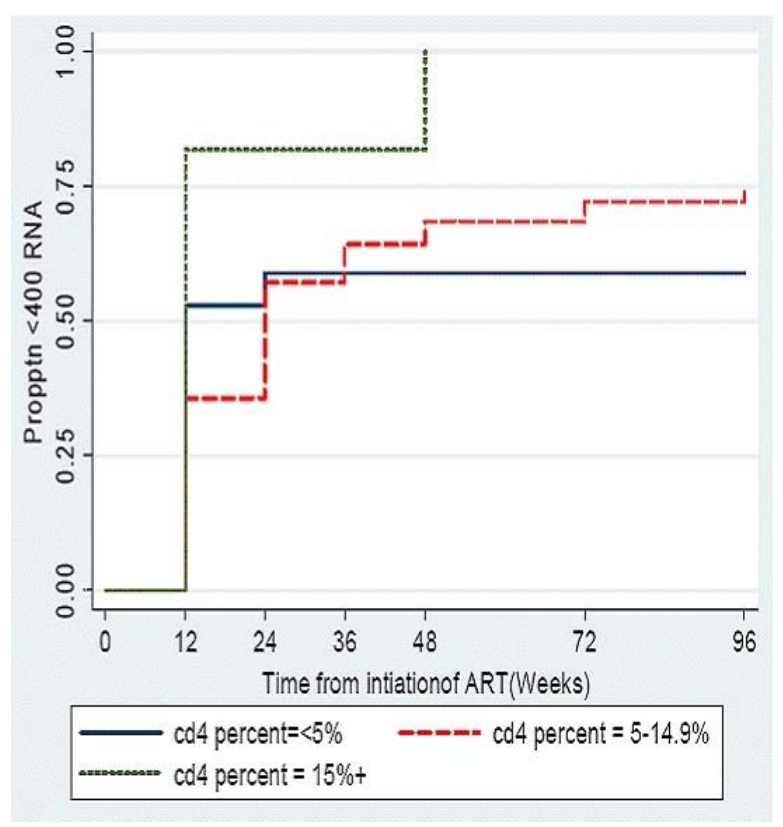




\section{Immunologic response to treatment}

The overall median CD4 cell percent increased from $11 \%$ (baseline) to $30 \%$ by 96 weeks post-HAART initiation ( $\mathrm{p}<0.001)$. Median (IQR) CD4 cell percent at 24,48 , and 96 weeks was $23.5 \%$ (15.9-30.6); $29 \%$ (22.0-34.0); and 30\% (25.0-36.0), respectively. Sixty percent of the children with a baseline CD4 cell percent $<5 \%$ achieved a CD 4 cell percent increase above $20 \%$ by 24 weeks (figure $3 \mathrm{a}$ ). This finding persisted through to 96 weeks of follow-up. In addition, children with a baseline CD4 cell percent

Figure 3a: Proportion of HIV-ienfected children on generic adult FDC HAART (Triomune achieving viral load $<400$ copies $/ \mathrm{ML}$

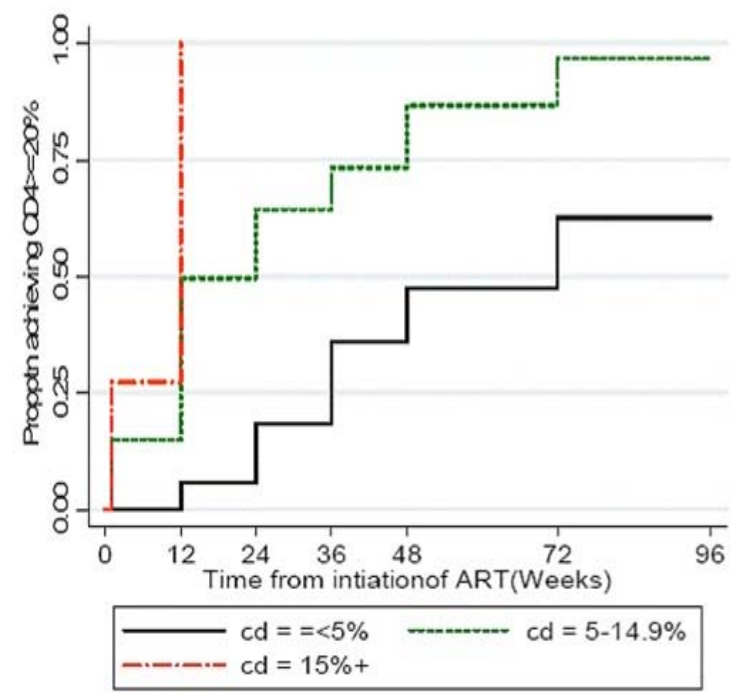

\section{Clinical response to treatment}

There was a clinical response to treatment with an increase in both mean HAZ and mean WAZ from 1.96 to -0.41 to 0.85 and -1.20 to 0.28 to 0.94 respectively at 48 and 96 weeks post-HAART initiation compared to baseline, which was statistically significant $(\mathrm{p}<0.001)$.

\section{Adherence to HAART}

The proportion of children who achieved $\geq 95 \%$ adherence at 24, 48, and 72 weeks was $96 \%, 91 \%$, and $93 \%$, respectively, based on clinic pill counts. The overall adherence rate was $\geq 95 \%$ in $90 \%$ (2555/ 2839) of the child visits.

\section{Multivariate analysis}

Children with a baseline CD4 cell percent greater than $15 \%$ were 3.0 times more likely to achieve
$<5 \%$ took a median time of 72 weeks to achieve a CD 4 cell percent $>20 \%$ compared to 12 weeks for those above $5 \%(\mathrm{p}<0.001)$. There was a gradual increase in the mean CD4 cell percent over time with the most rapid increase occurring within first 12 weeks of therapy (figure 3b). Median increase in CD4 cell count between 0-12 weeks, 12-24 weeks, 24-48 weeks and 48-96 weeks was 7.3\%, 4.6\%, 5.3\%, and $7.7 \%$ respectively. When the baseline CD4 cell percent was $<5 \%$ the median increase was modest with only a $6.1 \%, 0.8 \%, 9.0 \%, 3.0 \%$ rise respectively.

Figure 3b: Mean CD4 cell percent over time among HIV-infected children treated with generic FDC ART (Triomune) with 95\% CIs

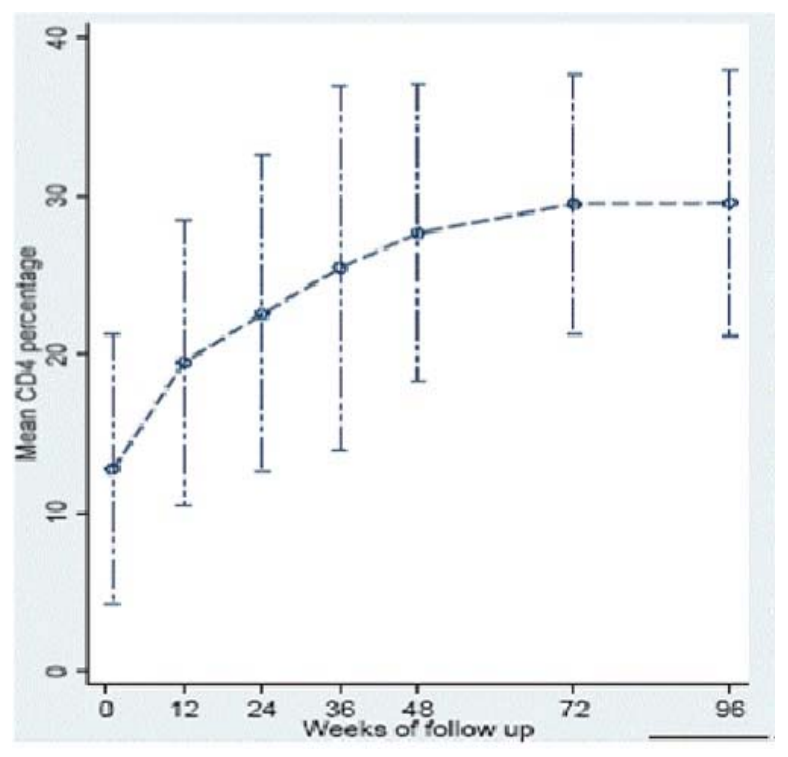

virologic success $(<400$ copies per $\mathrm{mL}$ ) than those who were severely immune suppressed(CD4 cell percent $<5 \%$ ) [table 3]. All other factors were not associated with virologic success.

\section{Adverse events and mortality}

Five children had adverse reactions of whom four presented with a NVP hypersensitivity rash (4\%), all of which were $\leq$ grade 2 and one with a grade 4 hepatitis $(1 \%)$. Elevated liver transaminases were reported in 3 other children, however all 3 were $\leq$ grade 2. There was one child who development acute renal failure and subsequently died but no other renal abnormalities were documented. A few children (4/104) developed anemia which was $\geq$ grade 2 , and all resolved. During the study, $6 \%$ $(6 / 104)$ of the children initiated on Triomune died. Of these, four deaths were within the first 12 weeks 
of HAART; their baseline CD4 cell percent ranged from $0.4 \%$ to $7.8 \%$. The other two deaths occurred after 44 and 56 weeks on therapy, respectively. The causes of death included toxoplasmosis, malaria, pneumonia, renal failure and severe diarrhea with dehydration.

Table 3: Predictors of Virologic Success for children on adult generic FDC (Triomune)

\begin{tabular}{|c|c|c|c|}
\hline Variable & $\begin{array}{l}\text { Unadjusted } \\
\text { HR }(95 \% \mathrm{CI})\end{array}$ & $\begin{array}{l}\text { Adjusted } \\
\text { HR }(95 \% \mathrm{CI})\end{array}$ & P-value \\
\hline \multicolumn{4}{|l|}{ Viral load } \\
\hline$\leq 750,000$ copy $/ \mathrm{mL}$ & ref & ref & \\
\hline$>750,000$ copy $/ \mathrm{mL}$ & $0.8(0.45-1.4)$ & $0.82(0.41-1.63)$ & 0.575 \\
\hline \multicolumn{4}{|l|}{ CD4 percent } \\
\hline$\leq 5 \%$ & ref & ref & \\
\hline$>5-14.9 \%$ & $1.17(0.59-2.3)$ & $1.37(0.65-2.86)$ & 0.406 \\
\hline$>15 \%$ & $2.31(0.97-5.47)$ & $3.03(1.10-8.32)$ & 0.031 \\
\hline \multicolumn{4}{|l|}{ Age } \\
\hline$\leq 3$ years & ref & ref & \\
\hline $3-5.9$ years & $1.05(0.57-1.94)$ & $0.99(0.50-2.00)$ & 1 \\
\hline$>6$ years & $1.05(0.59-1.86)$ & $1.2(0.54-2.60)$ & 0.682 \\
\hline \multicolumn{4}{|l|}{ WAZ } \\
\hline$>-2$ & ref & ref & \\
\hline$-3<-2$ & $1.068(0.63-1.82)$ & $1.23(0.65-2.34)$ & 0.576 \\
\hline$\leq-3$ & $1(0.4-2.52)$ & $1.26(0.44-3.60)$ & 0.670 \\
\hline \multicolumn{4}{|l|}{ HAZ } \\
\hline$>-2$ & ref & ref & \\
\hline$-3<-2$ & $1.18(0.69-2)$ & $1.34(0.72-2.50)$ & 0.36 \\
\hline$\leq-3$ & $0.84(0.46-1.53)$ & $0.87(0.40-1.89)$ & 0.728 \\
\hline \multicolumn{4}{|c|}{ Relationship of caregiver to child } \\
\hline Mother & ref & ref & \\
\hline Other* & $0.92(0.57-1.52)$ & $0.99(0.56-1.78)$ & 0.989 \\
\hline
\end{tabular}

* Father, Grandparent, Aunt, Sister

\section{Discussion}

Our findings from a pediatric HIV treatment program in a resource limited-setting show a good response to the long-term use of an adult FDC regimen with doses modified according to the children's weight. Our data demonstrate that pediatric HAART using generic adult FDC can be effective in a resource-limited settings, if other options are not available. The majority of children demonstrated satisfactory clinical, immunologic, and virologic response to antiretroviral treatment, noted as early as 12 weeks after initiation of HAART and sustained throughout the 96 weeks of follow-up. Over $75 \%$ of the children had viral $\log$ copies $>5.0$ at baseline and after 12 weeks of HAART $66 \%$ of the children had an undetectable viral load ( $<400$ copies per $\mathrm{mL}$ ). These findings are consistent with the other studies findings which have shown that HAART with generic adult FDC are safe and effective for HIV-infected children in resource limited settings, despite initiation of treatment during advanced stages of the disease $e^{7,11,12,21}$. Among the children who failed therapy in the study, caregiver, and age were not significant risk factors for virologic failure in this study group. However, all children with virologic failure had significant clinical and immunologic improvement. These findings confirm similar observations in prior studies ${ }^{22,23,24}$. Without access to viral load monitoring, those children who had virological failure would have appeared to be adequately responding to first-line ART, since all those who had virological failure had a good immunologic response. None of the children with detectable viral loads were switched to secondline therapy during the 96 weeks since all maintained a good immunologic response. More data are needed on long-term virologic response of children on ART in resource-limited settings.

As previously reported, we found that clinical monitoring for weight and height growth gains during HAART was useful and demonstrated that growth gains paralleled viral load and CD4 cell count 
improvements ${ }^{25}$. Anthropometric measurements are obtainable in most clinical settings and are therefore particularly useful in monitoring the initial response to ART in pediatric patients where immunologic and virologic monitoring may not be available. However, anthropometric measurements should be used in collaboration with immunologic monitoring because they are not a good predictor of treatment failure. Several prior studies of children on HAART in subSaharan Africa have demonstrated significant clinical outcomes (growth and CD4 cell) after 12 months on treatment $t^{7,8,26}$. The children in this study cohort also showed significant improvement in growth. However, this study did not include new WHO stage 3 and 4 events in the analysis for clinical response.

To prevent early mortality in children under 24 months of age WHO currently recommends that ART should be initiated early regardless of CD4 cell count ${ }^{27}$. This study also demonstrates that after 96 weeks of ART, children who were initiated with baseline CD $4>15 \%$ had a significantly higher probability of achieving virologic success compared to those with $\mathrm{CD} 4<5 \%$. In addition there appears to be poor immunologic reconstitution among the children who initiated ART with CD4 cell count $<5 \%$. These findings are similar to those reported in another Ugandan cohort of children which reported poor CD4 recovery compared to those in United Kingdom/Ireland probably due to lower CD 4 cell count at ART initiation ${ }^{28}$ A recent study from Thailand also reported that children with low CD4 percent and wasting at baseline were at high risk of mortality during the first 6 months of therapy ${ }^{21}$. These findings support the 2010 WHO recommendation of initiation of ART for children between 24-59 months at CD $4<25 \%$ and those 5 years and older at CD 4 absolute count $<350$ cells/ $\mathrm{mm}^{3}$, which was based on longitudinal data ${ }^{29,30}$.

Overall adherence to treatment based on pill counts was high, as previously reported ${ }^{17}$. The majority of children initiating HAART had good adherence $(>95 \%)$ when estimated by caretaker self-report ${ }^{17}$. Given the high rate of adherence, we could not examine the effect of poor adherence on virologic failure.

The use of adult FDC drugs in children also has some challenges. Since the tablets are formulated for adults, they must be halved or quartered in order to facilitate the appropriate dosing and therefore increase the risk of under or overdosing. A study of children in Malawi and Zambia showed that those who received quarter or half tablets of FDC were more frequently under dosed with NVP than children who received the whole tablet ${ }^{15}$. The investigators concluded that dividing FDC Triomune should be used with caution to avoid inappropriate dosing and that further study is needed on the effects of malnutrition on NVP pharmacokinetics in children. However in Thailand, good virologic and immunologic response as well as appropriate NVP exposure has been reported among children treated with adult fixed dose combinations of stavudine, lamivudine, and nevirapine (GPO-VIR) ${ }^{31}$. In spite of the disadvantages of using adult FDC to treat children, our data show that children can be effectively treated with adult FDC up to 96 weeks of treatment. Previous studies have reported good clinical and immunologic responses to HAART, but few have included virologic response.

While this study shows that adult generic FDC ART is feasible and effective for treatment of HIV infected children there is still an urgent need to increase access to new pediatric FDC formulations ${ }^{32}$. WHO currently has several generic pediatric FDCs on their pre-qualified drug list. in various combinations $^{33}$. Studies are needed to determine the long-term effectiveness and benefits of new pediatric FDC. Until pediatric FDC become widely available and as long as syrup formulations are not readily accessible due to their higher costs and relative complexity in use, adult FDC regimens can be a life saving and effective treatment for HIV-infected children in resource limited settings.

\section{Conclusion}

The use of generic adult FDC for treatment of HIVinfected Ugandan children was effective and led to sustained clinical, immunologic and virologic response during 96 weeks of antiretroviral therapy. Early initiation of ART is key to achieving both immunologic and virologic success.

\section{Acknowledgements}

The authors would like to thank the families and children who participated in the International leadership Award (ILA) study. Their commitment to this important study has advanced our knowledge and understanding of antiretroviral treatment for HIV infected children from resource-limited settings. We would also like to recognize the dedication of the ILA study staff (P. Ajuna, M. Owor, I. Kimuli, M. Luttajumwa, B. Musoke, G. Nalubega, M. Namwanjje, R. Kayondo, and P. Buyondo) based at Makerere University -Johns Hopkins University 
research collaboration and the support of the Elizabeth Glaser Pediatric AIDS Foundation (EGPAF) through the ILA grant. We thank Dr. Peter Mugenyi (JCRC, Kampala Uganda) and Prof. Mark Kline (Baylor College of Medicine, TX USA) for providing consultation in the early part of the study.

\section{Sources of support}

Elizabeth Glaser Pediatric AIDS Foundation, International Leadership Award Grant number: ILA-87-03

\section{References}

1. UNAIDS/WHO: Report on Global AIDS Epidemic. 2010. Available at: http:// www.unaids.org/globalreport/ global_report.htm.

2. Sutcliffe CG, van Dijk JH, Bolton C, Persaud D, Moss WJ. Effectiveness of antiretroviral therapy among HIV-infected children in sub-Saharan Africa. Lancet Infect Dis 2008; 8(8):477-489.

3. Marum L. BD, Guay L, et al. Three year mortality in a cohort of HIV -1 infected and uninfected Ugandan Children, Abstract WeB312. In: XI International Conference on AIDS STD: July 1996; Vancouver; 1996.

4. De Baets AJ, Bulterys M, Abrams EJ, Kankassa C, Pazvakavambwa IE. Care and treatment of HIV-infected children in Africa: issues and challenges at the district hospital level. Pediatr Infect Dis J 2007; 26(2):163-173.

5. Ministry of Health personal communication 2010.

6. Children Left Behind: Global stakeholder failing to adequately prevent and treat Pediatric HIV/ AIDS [http://www.globalaidsalliance.org/ newsroom/reports/]

7. O'Brien DP, Sauvageot D, Zachariah R, Humblet $\mathrm{P}$ : In resource-limited settings good early outcomes can be achieved in children using adult fixed-dose combination antiretroviral therapy. Aids 2006; 20(15):1955-1960.

8. Wamalwa DC, Farquhar C, Obimbo EM, Selig S, Mbori-Ngacha DA, Richardson BA, et al: Early response to highly active antiretroviral therapy in HIV-1-infected Kenyan children. $J$ Acquir Immune Defic Syndr 2007; 45(3):311-317.

9. Marazzi MC, Germano P, Liotta G, Buonomo E, Guidotti G, L. P: Pediatric highly active antiretroviral therapy in Mozambique: an integrated model of care. Minerva Pediatr 2006; 58(5):483-490.
10. Walker AS, Mulenga V, Ford D, Kabamba D, Sinyinza F, Kankasa C, et al. The impact of daily cotrimoxazole prophylaxis and antiretroviral therapy on mortality and hospital admissions in HIV-infected Zambian children. Clin Infect Dis 2007; 44(10):1361-1367.

11. Puthanakit T, Oberdorfer A, Akarathum N, Kanjanavanit S, Wannarit P, Sirisanthana T, et al. Efficacy of highly active antiretroviral therapy in HIV-infected children participating in Thailand's National Access to Antiretroviral Program. Clin Infect Dis 2005; 41(1):100-107.

12. Puthanakit T, Aurpibul L, Oberdorfer P, Akarathum N, Kanjanavanit S, Wannarit P, et al. Sustained immunologic and virologic efficacy after four years of highly active antiretroviral therapy in human immunodeficiency virus infected children in Thailand. Pediatr Infect Dis J 2007; 26(10):953-956.

13. Musoke PM, Barlow-Mosha L, Bagenda D, Mudiope P, Mubiru M, Ajuna P, et al. Response to antiretroviral therapy in HIV-infected Ugandan children exposed and not exposed to single-dose nevirapine at birth. J Acquir Immune Defic Syndr 2009; 52(5):560-568.

14. WHO: Scaling up antiretroviral therapy in resource limited settings: Treatment guidelines for a public health approach. Available at: http:/ Lwww.who.int/hiv/pub/prev care/en/ arvreviosion2003en.pdf In.; 2003.

15. Ellis JC, L'Homme RF, Ewings FM, Mulenga V, Bell F, Chileshe R, Molyneux E, et al: Nevirapine concentrations in HIV-infected children treated with divided fixed-dose combination antiretroviral tablets in Malawi and Zambia. Antivir Ther 2007;12(2):253-260.

16. Havens PL. Principles of antiretroviral treatment of children and adolescents with human immunodeficiency virus infection. Semin Pediatr Infect Dis 2003; 14(4):269-285.

17. Bagenda A, Barlow-Mosha L, Bagenda D, Sakwa R, Fowler MG, Musoke PM. Adherence to tablet and liquid formulations of antiretroviral medication for paediatric HIV treatment at an urban clinic in Uganda. Ann Trop Paediatr 2011; 31(3):235-245.

18. Williams PL, Storm D, Montepiedra G, Nichols S, Kammerer B, Sirois PA, et al. Predictors of adherence to antiretroviral medications in children and adolescents with HIV infection. Pediatrics 2006; 118(6):e1745-1757. 
19. Paterson DL, Swindells S, Mohr J, Brester M, Vergis EN, Squier C, et al. Adherence to protease inhibitor therapy and outcomes in patients with HIV infection. Ann Intern Med 2000; 133(1):2130.

20. Steele RG, Grauer D. Adherence to antiretroviral therapy for pediatric HIV infection: review of the literature and recommendations for research. Clin Child Fam Psychol Rev 2003; 6(1):17-30.

21. Collins IJ, Jourdain G, Hansudewechakul R, Kanjanavanit S, Hongsiriwon S, Ngampiyasakul $\mathrm{C}$, et al: Long-term survival of HIV-infected children receiving antiretroviral therapy in Thailand: a 5-year observational cohort study. Clin Infect Dis 2010;51(12):1449-1457.

22. Johnston AM, Valentine ME, Ottinger J, Baydo R, Gryszowka V, Vavro C, et al. Immune reconstitution in human immunodeficiency virusinfected children receiving highly active antiretroviral therapy: a cohort study. Pediatr Infect Dis J 2001; 20(10):941-946.

23. Essajee SM, Kim M, Gonzalez C, Rigaud M, Kaul A, Chandwani S, Hoover W, et al: Immunologic and virologic responses to HAART in severely immunocompromised HIV-1-infected children. Aids 1999;13(18):25232532.

24. Ghaffari G, Passalacqua DJ, Caicedo JL, Goodenow MM, Sleasman JW. Two-year clinical and immune outcomes in human immunodeficiency virus-infected children who reconstitute CD4 T cells without control of viral replication after combination antiretroviral therapy. Pediatrics 2004; 114(5):e604-611.

25. Musoke PM, Mudiope P, Barlow-Mosha LN, Ajuna P, Bagenda D, Mubiru MM, et al Growth, immune and viral responses in HIV infected African children receiving highly active antiretroviral therapy: a prospective cohort study. BMC Pediatr 2010; 10:56.

26. Reddi A, Leeper SC, Grobler AC, Geddes R, France KH, Dorse GL, Vlok WJ, et al: Preliminary outcomes of a paediatric highly active antiretroviral therapy cohort from KwaZulu-Natal, South Africa. BMC Pediatr 2007; 7:13.

27. Violari A, Cotton MF, Gibb DM, Babiker AG, Steyn J, Madhi SA, Jean-Philippe P, McIntyre JA: Early antiretroviral therapy and mortality among HIV-infected infants. N Engl J Med 2008; 359(21):2233-2244.

28. Kekitiinwa A, Lee KJ, Walker AS, Maganda A, Doerholt K, Kitaka SB, Asiimwe A, et al Differences in factors associated with initial growth, CD4, and viral load responses to ART in HIV-infected children in Kampala, Uganda, and the United Kingdom/Ireland. J Acquir Immune Defic Syndr 2008, 49(4):384-392.

29. WHO: Antiretroviral therapy for HIV infection in infants and children Recommendations for a public health approach. . 2010.

30. Dunn D: Short-term risk of disease progression in HIV-1-infected children receiving no antiretroviral therapy or zidovudine monotherapy: a meta-analysis. Lancet 2003; 362(9396):1605-1611.

31. Chokephaibulkit K, Plipat N, Cressey TR, Frederix K, Phongsamart W, Capparelli E, et al Pharmacokinetics of nevirapine in HIV-infected children receiving an adult fixed-dose combination of stavudine, lamivudine and nevirapine. Aids 2005; 19(14):1495-1499.

32. Dionisio D, Gass R, McDermott P, Racalbuto V, Madeo M, Braghieri G, et al: What strategies to boost production of affordable fixed-dose anti-retroviral drug combinations for children in the developing world? Curr HIV Res 2007; 5(2):155-187.

33. WHO List of Prequalified Medicinal Products. 2011. Available at: http://apps.who.int/prequal/ query/productregistry.aspx?list $=$ tb. 